\title{
Drug use in English professional football
}

\author{
I Waddington, D Malcolm, M Roderick, R Naik
}

Br J Sports Med 2005;39:e18 (http://www.bjsportmed.com/cgi/content/full/39/4/e18). doi: 10.1136/bjsm.2004.012468

See end of article for authors' affiliations ........................

Correspondence to: Professor Waddington, 5 Roundhill Road, Leicester LE5 5RJ, UK; ivan.waddington@ ntlworld.com

Accepted 6 April 2004
Objectives: To examine several issues related to drug use in English professional football. More particularly the project sought to gather data on: players' use of permitted supplements (mineral and vitamin pills and creatine); whether they sought advice, and if so from whom, about their use of supplements; their experience of and attitudes towards drug testing; their views on the extent of the use of banned performance enhancing and recreational drugs in football; and their personal knowledge of players who used such drugs.

Methods: With the cooperation of the Professional Footballers Association (PFA), reply paid postal questionnaires were delivered to the home addresses of all 2863 members of the PFA. A total of 706 questionnaires were returned, a response rate of just under $25 \%$.

Results: Many players use supplements, although almost one in five players does so without seeking qualified professional advice from anyone within the club. Blood tests are rarely used to monitor the health of players. One third of players had not been tested for drugs within the preceding two years, and $60 \%$ felt that they were unlikely to be tested in the next year. The use of performance enhancing drugs appears to be rare, although recreational drugs are commonly used by professional footballers: $6 \%$ of respondents indicated that they personally knew players who used performance enhancing drugs, and $45 \%$ of players knew players who used recreational drugs.

Conclusions: There is a need to ensure that footballers are given appropriate advice about the use of supplements in order to minimise the risk of using supplements that may be contaminated with banned substances. Footballers are tested for drugs less often than many other elite athletes. This needs to be addressed. The relatively high level of recreational drug use is not reflected in the number of positive tests. This suggests that many players who use recreational drugs avoid detection. It also raises doubts about the ability of the drug testing programme to detect the use of performance enhancing drugs.
O ver the last two decades a growing amount of evidence has become available about the extent of llicit drug use in many sports. Although much of this evidence has been anecdotal, some has come from relatively reliable sources-for instance, evidence given to parliamentary or judicial inquiries under oath. For example, in Canada the Dubin Inquiry, ${ }^{1}$ established after the positive test of Ben Johnson at the 1988 Seoul Olympics, provided detailed information about the use of banned substances in many sports, particularly in Canada but also in several other countries. Similarly detailed and relatively reliable information about the use of performance enhancing drugs in sport was provided by the US Senate Judiciary Committee Hearing on Steroid Abuse in America in $1989^{2}$ and by a report on Drugs in Sport presented to the Australian Parliament in 1989. ${ }^{3}$ More recently, the revelations by the French customs and police in the 1998 Tour de France, and the subsequent criminal trials in France, have provided incontrovertible evidence that the use of drugs in cycling is widespread, systematic, and organised. ${ }^{4}$

Although there has recently been a study of drug use in amateur footballers in Cameroon, ${ }^{5}$ there are almost no systematic or reliable data about the extent of drug use in professional football. We do know that the use of performance enhancing drugs in football is not new: in Forward Arsenal, published in 1952, the Arsenal and England player Bernard Joy described Arsenal's use of "pep pills" before an FA Cup match against West Ham United in the 1924-25 season. ${ }^{6}$ The fact that Joy was perfectly open about Arsenal's use of stimulants, and that his matter of fact style of writing is devoid of any suggestion that Arsenal might have been cheating or doing anything improper, provide an interesting sidelight on attitudes to performance enhancing drugs in the period before their use in sport was banned.

The object of this study was to gather relatively reliable data on a number of issues related to drug use in English professional football. More particularly we sought to gather data on: players' use of supplements (mineral and vitamin pills and creatine); whether they sought advice, and if so from whom, about their use of supplements; their experience of and attitudes towards drug testing; their views on the extent of the use of banned performance enhancing and recreational drugs in football; and their personal knowledge of players who used such drugs.

\section{METHODS}

The research reported here was undertaken with the cooperation of the Professional Footballers Association (PFA). Reply paid postal questionnaires were delivered by the researchers to the PFA who in turn sent them to the home addresses of all 2863 members. In addition to the questionnaire, each PFA member received letters from the director of the project and the Chief Executive of the PFA, Gordon Taylor, both of which guaranteed anonymity to respondents. This was felt to be important, given the sensitive issues raised by some questions. A total of 706 questionnaires was returned, giving a response rate of just under 25\%. This was considered satisfactory in view of the fact that, firstly, although the questionnaire did not ask about players' own use of drugs, it still dealt with some sensitive issues, and, secondly, there was an even spread of responses from players of different kinds, as documented below, suggesting that a representative sample was obtained.

Surveys are now a well established means of obtaining an indication of the extent of drug use in sport, although most 
surveys have been self use surveys and have been conducted on adolescents in schools and colleges. This probably reflects the fact that researchers often have easy access to large numbers of students in the institutions in which they work, that access to large numbers of elite athletes is restricted, and that elite athletes are generally reluctant to discuss drug use in their sport. ${ }^{7}$ In its focus on professional players, this survey is therefore rather unusual.

It is not, however, unique. There have been a few surveys of elite or professional athletes, some of which, like the present one, did not ask elite athletes about their personal use of drugs but, instead, asked them to estimate how many athletes in their sport used drugs. ${ }^{8} 9$ This indirect survey technique is probably less threatening as it does not ask directly about the athlete's own use of drugs and may therefore encourage a higher response rate.

It is important to note that, in this study, players were not just asked to estimate what proportion of players use drugs, but also whether they personally knew players, either in their current or a former team, who used drugs. Whereas estimates are almost bound to contain a margin of error, the latter question asks, not for players' subjective views or estimates, but about their personal knowledge of players with whom they have actually played and who have used drugs.

\section{RESULTS}

Almost 94\% of respondents were on current professional contracts, $6 \%$ were ex-players, and $0.3 \%$ were apprentice players. Almost 22\% played for clubs in the Premier League, $25 \%$ played for clubs in Division One of the Nationwide League, $26 \%$ played for clubs in Division Two, and 27\% for clubs in Division Three. In terms of age, $2 \%$ were aged 18 or under, $41 \%$ were aged $19-24,31 \%$ were aged $25-30$, and $25 \%$ were 31 or over. Respondents were also asked about the number of first team matches in which they had played in that season, in order to differentiate between regular first team players and "squad" players and others who appeared less regularly in the first team. All but $13 \%$ of respondents had played in their club's first team that season (the questionnaire was distributed two thirds of the way through the 2002-2003 season), with 9\% making between one and five first team appearances, 7\% making 6-10 appearances, 7\% making 11-15 appearances, and $64 \%$ had played in 16 or more first team games. The fact that responses were well distributed between players of different ages, players in different leagues/divisions, and players who were regular first team players and those who played less often suggests that our respondents constituted a relatively representative group of professional players.

\section{Use of supplements}

Many players use supplements of one kind or another. Almost 58\% reported using vitamin pills, $23 \%$ used mineral pills, $24 \%$ used protein powders, and $37 \%$ used creatine. Given that it is important for players to maintain high levels of health and fitness, these data are not surprising, as the use of legitimate drugs has become increasingly important in the training regimens of many elite athletes. ${ }^{10}$ Indeed, if there is anything surprising in these findings, it is that footballers use rather fewer supplements than have been reported for some other athletes, particularly those in track and field. ${ }^{11}$

In terms of taking advice on supplement use, $28 \%$ of players reported taking advice from the club physiotherapist, $21 \%$ from a fitness trainer, and a further $21 \%$ from another sports scientist, such as a nutritionist. The club doctor was the least used source of advice, being used by just 15\% of players. Almost one in five players (18\%) reported that they used supplements without taking advice from any of the above.
Blood tests, which might be used to monitor the health of players, are hardly ever used. Seven out of eight players $(87 \%)$ reported that their club never performed blood tests on players, although there is a clear tendency for clubs in the higher divisions, particularly the Premier League, to use blood tests. Fewer than 5\% of players in Second and Third Division clubs reported that their clubs took blood samples from players, but this figure increases to $11 \%$ for players in Division One of the Nationwide League and to 36\% for players in the Premier League.

\section{Experience of drug testing}

Almost two thirds (65\%) of players reported having been tested for the use of banned drugs in the preceding two years, $33 \%$ having been tested once, $18 \%$ tested twice, and $14 \%$ tested three times or more. However, one third of all players (35\%) reported that they had not been tested in the preceding two years. A substantial majority of players $(60 \%)$ felt that they were unlikely to be tested for drugs in the next 12 months, compared with $40 \%$ who felt they were likely to be tested. Only $8 \%$ of players reported having been tested for drugs as part of their medical when they signed for their club. Drug testing was felt to be "certainly" or "probably" a deterrent to the use of drugs by $73 \%$ of players, compared with 23\% who felt it "certainly" or "probably" did not act as a deterrent; $4 \%$ expressed no opinion.

\section{Use of performance enhancing drugs}

In what was undoubtedly the most sensitive part of the questionnaire, players were asked to estimate, in the light of their own experience, what proportion of players were using performance enhancing drugs, and then asked whether they personally knew players who used such drugs. These questions were then asked again in relation to recreational drugs. To make sure that the question was clear, the questionnaire listed examples of performance enhancing (anabolic steroids, stimulants) and recreational (cannabis, cocaine) drugs.

A half of all players (49\%) felt that there was no use of illicit performance enhancing drugs in professional football. About a third of players (34\%) felt that performance enhancing drugs were being used by some players, although the great majority felt that their use was rare. In this regard, $23 \%$ of players felt that performance enhancing drugs were used by under $2 \%$ of players; $8 \%$ felt that $3-5 \%$ of players used such drugs, and just over 3\% felt that performance enhancing drugs were being used by $6 \%$ or more of their fellow professionals; $17 \%$ of players had no opinion as to whether or not drugs were being used.

Almost $6 \%$ of respondents (39 players in total) indicated that they personally knew players who used performance enhancing drugs. These respondents were spread across all four divisions, with $18 \%$ playing for Premier League clubs, $24 \%$ for clubs in Division One of the Nationwide League, 36\% for Second Division clubs, and $21 \%$ for clubs in Division Three. Of the players who indicated that they knew players who used performance enhancing drugs, $68 \%$ indicated that the drug using players were at a previous club, $20 \%$ indicated that the drug using players were at their current club, and $12 \%$ indicated that they knew drug using players at both their current and previous clubs. Four Premier League players, two First Division players, four Second Division players, and four Third Division players indicated that they knew players at their current club who used performance enhancing drugs.

\section{Use of recreational drugs}

Our data indicate that the use of recreational drugs is considerably more widespread than is the use of performance enhancing drugs. Only $29 \%$ of players felt that recreational 
drugs were not used by professional footballers. Almost $28 \%$ of respondents felt that recreational drugs were used by fewer than $2 \%$ of players, $13 \%$ felt that $3-5 \%$ of players used recreational drugs, $9 \%$ felt that they were used by $6-10 \%$ of players, and $4 \%$ felt that recreational drugs were used by $11 \%$ of players or more; $18 \%$ of players had no opinion about how widely they were used.

Approaching a half of all players (45\%) indicated that they personally knew players who used recreational drugs. Among Premier League players, $31 \%$ personally knew players who used such drugs, compared with $45 \%$ of players in the First Division of the Nationwide League, $44 \%$ of Second Division players, and $52 \%$ of Third Division players. Of those who knew players who use recreational drugs, 15\% indicated that the players who used such drugs were at their present club, $63 \%$ indicated the drug using players were at a previous club, and $23 \%$ knew players at both their current and previous clubs who used recreational drugs. In all, 16 Premier League players, 23 First Division players, 21 Second Division players, and 39 Third Division players indicated that they knew players at their current club who used recreational drugs.

\section{Attitudes towards penalties for drug use}

Players felt that, on the whole, the punishment for using banned substances was of the correct severity. Some 59\% of players felt that the punishment for using performance enhancing drugs was "about right", whereas $25 \%$ felt it was "not severe enough". Only 3\% felt the punishment was "too severe", with 13\% having no opinion. Attitudes towards the use of recreational drugs were, perhaps not surprisingly in view of their more widespread use, less punitive. Some 53\% of players felt that the punishment for using recreational drugs was "about right", compared with $20 \%$ who felt that it is "not severe enough", and 13\% who felt that the punishment is "too severe"; $14 \%$ had no opinion.

Finally, players were asked, firstly, if they would take a performance enhancing drug if it could guarantee them selection for their national side in the next World Cup, and, secondly, about their knowledge of the guidelines on drug use published by UK Sport.

Just $5 \%$ indicated that they would be prepared to use drugs, the remainder rejecting the use of drugs, even if this could guarantee them a place in their national side for the World Cup. Almost $68 \%$ of players indicated that they were aware of UK Sport's guidelines on drug use, and the remaining $32 \%$ were not.

\section{DISCUSSION \\ Use of supplements}

That many players use supplements is not surprising. However, some aspects of players' use of supplements merit further comment. This is particularly the case in relation to seeking advice about the use of supplements. In this regard it is interesting to note that the club doctor, who would normally be the person with the highest medical qualification on the club's staff, is the person who is least often consulted by players about their use of supplements. This finding confirms the results of an earlier study of club doctors, which noted the marginal role of the doctor in many clubs, particularly in the lower divisions, in which the club doctor "may not attend the club or see the players routinely at all between home matches". ${ }^{12}$

Of particular concern is the fact that almost one in five of our sample indicated that they used supplements without taking any specialist advice from within the club. This is a matter of concern for two reasons. Firstly, the earlier study of club doctors, noted above, also found that players were sometimes using creatine without specialist advice. For example, some players purchased their supplies of creatine from a local gym, and, along with the purchase, they sometimes received advice on its use. The authors of that report expressed concern "about the quality of advice which players receive from this and other non-professional sources and, in particular ... that some players may be given advice which encourages them to use creatine in excessively high and potentially dangerous doses". One player who was interviewed for that study reported being admitted to hospital and diagnosed as having a kidney malfunction caused by very high doses of creatine. On the basis of these findings, that study recommended that when creatine is given to players, "its use should be supervised and the players' health monitored" ${ }^{12}$ We believe that continues to be good advice.

The second reason for concern relates to the fact that numerous sporting organisations, including the IOC and WADA, have repeatedly warned that supplements may be contaminated with banned substances. The latest advice to UK athletes, contained in a joint statement issued by UK Sport, the BOA, and several other organisations, says that athletes "are strongly advised to be extremely cautious about the use of any supplements". It notes that a recent study carried out for the IOC found that $15 \%$ of tested supplements contained banned substances. It emphasises that anti-doping rules are based on the principle of strict liability and advises that athletes should "always consult a qualified medical practitioner, accredited sports dietician and/or registered nutritionist before taking supplements" ${ }^{13}$ It is clear that players who use supplements without such professional advice are at risk of inadvertently consuming banned substances.

\section{Players' experience of drug testing}

Although, in absolute terms, the number of drug tests carried out in football is relatively large-in 2001-2002 UK Sport conducted 1137 drug tests on behalf of the Football Association $^{14}$ - the fact that there is also a large number of professional players means that professional footballers are tested for drugs much less frequently than are most other elite athletes in England. Our data indicate that, on average, only about one third of professional footballers will be tested in any given year. This compares unfavourably with the situation in many other sports. A Sports Council survey of the experiences of elite athletes in 1995 found that, in the preceding 12 months, $77 \%$ of elite track and field athletes had been tested by the Sports Council, and 37\% had been tested by another agency. ${ }^{15}$

The Sports Council survey also found that $83 \%$ of elite British athletes in track and field felt that they were either certain $(28 \%)$ or likely $(55 \%)$ to be tested in competition in the next 12 months, and $77 \%$ felt it was certain or likely that they would be tested out of competition. By contrast, just $40 \%$ of footballers felt that they were either certain (just $2 \%$ ) or likely $(38 \%)$ to be tested in the next 12 months. A system of testing that allows a substantial majority $(60 \%)$ of players to say, perfectly realistically, that they do not expect to be tested in the next 12 months is not one that is likely to command respect either in other sports or in other countries. This is an issue that the Football Association needs to review as a matter of urgency.

\section{Use of drugs}

Data from UK Sport indicate that, over the period from 1988 to 2001-2002, there were in Britain 89 positive drug tests in football (these data include the results of testing on behalf of the Welsh and Scottish Football Associations, as well as the English Football Association). The most commonly detected drugs in football were Class 1A stimulants such as pseudoephedrine and metabolites of cocaine, of which there 
were 40 positive cases, and marijuana, for which there were 29 positive test results. ${ }^{16}$ It is probably the case that the metabolites of cocaine were associated with recreational drug use rather than with drugs taken for performance enhancing reasons. However, there were also six positive tests for anabolic agents in this period. Over the whole period, there were, on average, six positive tests for banned substances (recreational and performance enhancing) per year.

Our data suggest that the use by professional footballers of banned substances is considerably more widespread than the number of positive test results would suggest. This is not surprising, as there is a widespread recognition among informed observers that the number of positive test results is a very poor-indeed almost worthless-indication of the extent of drug use in sport, and it is widely recognised that those who test positive represent the tip of a much larger iceberg. ${ }^{14}$

What then can we say about our data on the use of drugs in professional football? Firstly, they provide clear evidence that performance enhancing drugs are being used by some professional footballers in England; this is clear from the fact that $6 \%$ of players in our sample indicated that they personally knew current or former team-mates who used performance enhancing drugs. It is important to emphasise the purely factual nature of the question in this regard; players were not asked to try to estimate the extent of drug use in football but were asked, in a purely factual way, whether they personally knew players who used performance enhancing drugs and, if so, whether such players were in their current or a former team.

Of course, data of this kind do not provide a precise indication of the extent of drug use, as it is possible that different respondents could have been referring to the same drug using player(s). To some extent, this will almost certainly have happened. However, the degree to which it happened was probably quite limited. In this regard it is important to emphasise that the key question asked players if they personally knew players who used drugs, and it is likely that there would be only a limited overlap between players who were personally known by, for example, a player with a London based Premier League team and those who were personally known by a player with a Second or Third Division club based in the west or north of England, or Wales. Moreover, the design of the questionnaire meant that there was a limit to which such "double counting" could have taken place. More specifically, it should be emphasised that we can eliminate the possibility that we are dealing with just one or two players whose drug using habit was known to all 39 respondents who identified a current or former team-mate who used drugs. It was partly in order to eliminate this possibility that we asked whether the drug using players were at the respondent's current club or a previous club. As we noted earlier, of the 39 players who indicated that they personally knew players who used performance enhancing drugs, 14 indicated that they knew players at their current club who used such drugs. It is quite clear that the four Premiership players who knew players at their current club who used drugs could not have been referring to the same drug using players as those cited by the two First Division

\section{What is already known on this topic}

Over the last two decades a growing amount of evidence has become available about the extent of illicit drug use in many sports. However, there are no systematically collected or reliable data on the extent of drug use in professional football. players who knew drug using players at their current club, and that these in turn must have been different from the players cited by the four Second Division players and the four Third Division players.

Although the survey provides clear evidence that performance enhancing drugs are being used in professional football, the data also indicate that the use of such drugs is relatively limited, in two respects. Firstly, their use would seem to be much more limited in football than appears to be the case in many other sports, most notably track and field, cycling, weightlifting and powerlifting, and swimming. ${ }^{4}$ Secondly, there are some patchy data that suggest that the use of performance enhancing drugs in English football may also be relatively low in relation to their use in football in some other European countries. We have in mind here, in particular, recent scandals leading to judicial investigations into doping in Italian football, where the use of performance enhancing drugs may-we emphasise "may" - have been relatively highly organised in the 1990s.

But if the use of performance enhancing drugs appears to be relatively rare in football, it is clear that the use of recreational drugs is relatively common. Particularly striking in this regard is the finding that $45 \%$ of players personally knew players who used such drugs. Again, there is the possibility of some, probably limited, "double counting"; however, it is clear that the 16 Premier League players who knew players at their current club who used such drugs cannot be referring to the same drug using players as those cited by the 23 First Division players, and that these in turn must have been different from the players cited by the 21 Second Division players and the 39 Third Division players.

That the use of recreational drugs is common among professional footballers is, perhaps, hardly a surprising finding, as data from the European Monitoring Centre for Drugs and Drug Addiction (EMCDDA) indicate that recreational drug use is common in the general population, especially young men. The most recent data from EMCDDA indicate that, in Britain in 2001-2002, 34\% of adults aged 1659 had at some time in their lives used an illicit drug, and $12 \%$ had used such drugs in the preceding 12 months. There are significant sex differences, with rates for drug use among men being almost 50\% higher than those in women. The figures for young people are much higher, with $49 \%$ of 16-24 year olds in 2001-2002 reporting having used illicit drugs; $29 \%$ reported using such drugs in the preceding 12 months and $19 \%$ reported using them in the preceding month. ${ }^{17}$ Given the high level of recreational drug use in the wider society, it would perhaps be unrealistic to imagine that their use would not be common among professional footballers who, in demographic terms, are in the high risk group of young men.

There is, however, one other implication of the findings about recreational drug use among footballers which needs to be examined. The relatively high level of recreational drug use indicated by our survey is not reflected in the number of positive tests: as noted earlier, very few players (on average just six a season from some 1100 tests a season) test positive.

\section{What this study adds}

This is the first systematic study designed to gather relatively reliable data on a number of issues related to drug use in English professional football. The study generated data on: players' use of supplements; players' experience of and attitudes towards drug testing; players' views on the extent of illicit drug use in professional football and their personal knowledge of players who use banned drugs. 
This indicates that many players who are using recreational drugs are not testing positive within that testing programme. If it is relatively easy-as it appears to be-for players who are using recreational drugs to avoid detection, then this must raise doubts about the ability of the testing programme to detect the use of performance enhancing drugs. This is a serious question which needs to be addressed by the football authorities.

\section{CONCLUSION}

This paper raises a number of issues relating to players' use of supplements, the nature of the drug testing programme in football, and players' use of performance enhancing and recreational drugs.

\section{Use of supplements}

We recommend that clubs take steps to ensure that all players are provided with appropriate advice on the use of supplements. Good practice for monitoring both the general health of players and their need for, and use of, supplements would also involve regular analysis of blood samples taken from players.

\section{Drug testing}

Professional footballers are tested for drugs less often than are most other athletes and much less often than are elite track and field athletes. This is a matter that needs to be addressed.

\section{Players' use of drugs}

Although this study indicates that the use of recreational drugs by professional footballers is common, there is no evidence to suggest that the use of performance enhancing drugs is common. There is, however, no room for complacency. It is clear that, as the rewards associated with football success continue to increase, the pace and intensity of the game increase, and the pressures on players to perform, over long periods of time and at the highest level, continue to grow, so the pressures on players to use performance enhancing drugs are also likely to increase rather than decrease. The football authorities in Britain need to keep their policies and practices under review.

\section{Authors' affiliations \\ I Waddington, Visiting Professor at University College Chester, UK, University College Dublin, Ireland, and the Norwegian University of Sport and Physical Education, Oslo, Norway}

D Malcolm, M Roderick, Centre for the Sociology of Sport, University of Leicester, Leicester, UK
R Naik, General practitioner and orthopaedic physician, 1 Far Lane, Sheffield S6 4FA, UK

Competing interests: none declared

\section{REFERENCES}

1 Dubin, The Hon Charles L. Commission of Inquiry into the Use of Drugs and Banned Practices Intended to Increase Athletic Performance. Ottawa: Canadian Government Publishing Centre, 1990.

2 US Congress. Committee of the Judiciary of the US Senate. Hearing on steroid abuse in America, April 31989.

3 Australian Parliament. Drugs in Sport: an Interim Report of the Senate Standing Committee on Environment, Recreation and the Arts. Commonwealth of Australia, 1989.

4 Waddington I. Sport, health and drugs. London: E \& F N Spon, 2000:153-69.

5 Ama PFM, Betnga B, Ama Moor VJ, et al. Football and doping: study of African amateur footballers. Br J Sports Med 2003;37:307-10.

6 Joy B. Forward Arsenal: the Arsenal story, 1888-1952. London: Phoen House, 1952

7 Mottram D. Prevalence of drug misuse in sport. In: Mottram D, ed. Drugs in Sport.3rd ed. London: Routledge, 2003:369.

8 Scarpino V, Arrigo A, Benzi G. Evaluation of prevalence of doping among Italian athletes. Lancet 1990;336:1048-50.

9 Anshel MH. A survey of elite athletes on the perceived causes of using banned drugs in sport. Journal of Sport Behaviour 1991;14:283-307.

10 Houlihan B. Dying to win. Strasbourg: Council of Europe, 1999:32.

11 Voy R. Drugs, sport and politics. Champaign, IL: Leisure Press, 1991:99.

12 Waddington I, Roderick M, Parker G. Managing injuries in professional football: the roles of the club doctor and physiotherapist. Centre for Research into Sport and Society: University of Leicester, 1999.

13 Position Statement of UK Sport, the British Olympic Association (BOA), the British Paralympic Association (BOPA), National Sports Medicine Institute (NSMI) and the Home Country Sports Council (HCSC), 2003. www.uksport. gov.uk/generic_template.asp?id = 12179 (accessed 26 Jan 2004)

14 UK Sport. Anti-doping report, 2001/2002. London: UK Sport, 2002:8.

15 Sports Council. Doping control in the UK: a survey of the views of elite competitors 1995. London: Sports Council, 1996:14.

16 UK Sport. Anti-doping report 2001/2002. London: UK Sport, 2001:41.

17 European Monitoring Centre for Drugs and Drug Addiction. United Kingdom drug situation 2001. http://annualreport.emcdda.eu.int/en/home-en.html (accessed 17 Feb 2004)

\section{COMMENTARY}

The article is highly important. It is based on a survey which is the first empirical survey on doping in soccer/football ever. The results are clearly weighted and provide evidence for the medical sector as well as having clinical importance for therapy-for example, by knowing facts about supplement use and drug abuse-which has great value because players normally do not talk about drug taking and side effects with medical doctors or the health sector.

G W Spitzer

Sport Science/Sociology, Humboldt University Berlin, Witzlebenstr 12, Berlin D-15057, Germany; spitzerg@hu-berlin.de 